\title{
DETECTION OF PROSAPOSIN AND MATURE SAPOSINS IN GOAT MILK
}

\author{
${ }^{1}$ Andrea Robertson Byers, ${ }^{2}$ Salam Ibrahim and ${ }^{1}$ Mulumebet Worku \\ ${ }^{1}$ Department of Animal Sciences, \\ ${ }^{2}$ Family and Consumer Sciences \\ North Carolina Agricultural and Technical State University, Greensboro, USA
}

Received 2013-12-16; Revised 2014-07-24; Accepted 2014-10-31

Funding: Title III and SAES Agricultural Research Program

Competing Interests: The authors have declared that no competing interests exist

\begin{abstract}
Increased scientific knowledge related to the nutritional, functional and biological activities and health benefits of goat milk is needed to further promote goat farming, goat milk and traditional or innovative neutraceuticals as a basis for socio-economic benefit. Identification and characterization of milk derived Prosaposin is essential to development of neutraceuticals from goat milk that maybe beneficial to human health. The objectives of this study were to detect Prosaposin and its mature proteins in milk from different breeds of goats. Raw milk was collected from eight different breeds of goat. Whey fractions were separated by high speed centrifugation. Extracts were analyzed by electrophoresis using the Pharmacia Phastsystem (GE Healthcare) in $12.5 \%$ homogeneous gels. Gels were silver stained to analyze total protein. Phastsystem diffusion immunoblotting with HRP enzyme-labeled polyclonal anti-Prosaposin, anti-saposin and a tetramethylbenzidine substrate was used to identify specific proteins. Multiple proteins were observed in whey fractions from all animals tested. Antibodies detected a 70-65 kDa Prosaposin band and a 12-14 kDa saposin $\mathrm{C}$ band in all goat breeds. Both Prosaposin and its derivative saposin A, B, C and D were detected in caprine milk. These studies show that Prosaposin is present in milk from different breeds of goats contributing to therapeutic attributes of goat milk. The biological activity of saposins such as the neurotrophic activity of goat saposin $\mathrm{C}$ need further characterization.
\end{abstract}

Keywords: Milk, Neutraceutical, Prosaposin, Saposin, Neurotrophic

\section{INTRODUCTION}

Milk proteins are of interest in human nutrition because of their involvement in a wide range of nutritional, functional and biological activities. The biological activities are due to the peptides and proteins in milk. Studies have identified a large number of peptide sequences in the major milk proteins that exhibit specific bioactivities affecting the digestive, cardiovascular, immune and nervous systems (Chessa et al., 2009). Some biological activities of milk proteins occur upon proteolytic action. Bioactive peptides are produced during the digestive process and are defined as specific protein fragments that have a positive impact on body functions or conditions and may influence health. According to Slacanac et al. (2010), the proteins of caprine milk are more digestible than those of bovine milk. Also, better absorption of the amino acids from caprine milk in comparison with those of bovine milk in the human digestive tract was reported by Haenlein (2004). One of the most significant roles of caprine milk compared to bovine milk is its hypoallergenic value, fifty percent of the human population who are allergic to bovine milk tolerated caprine milk (Park, 1994). Studies have shown Corresponding Author: Andrea Robertson Byers, Department of Animal Science, North Carolina Agricultural and Technical State University, Greensboro, USA 
caprine milk to have many therapeutic effects, such as, a reduction in cholesterol levels and improvement in iron bioavailabilty in rats with induced ferropenic anemia in comparison to bovine milk (Slacanac et al., 2010). Better digestibility of caprine milk proteins and a softer curd of fermented caprine milk products compared to bovine milk suggest that caprine milk could be used as an alternative food in the diet of patients suffering with ulcers and ulcerative colitis (Slacanac et al., 2010).

Prosaposin (PSAP) is a sphingolipid activator protein and precursor of lysosomal saposins A, B, C and D. It plays a role in the development, maintenance and repair of the nervous system and is present in high concentrations in humans and other mammals (Taylor et al., 2000). Studies by Jolivalt et al. (2008) have shown impaired Prosaposin secretion during nerve regeneration in diabetic rats and protection of nerve regeneration by a Prosaposin-derived peptide. Their results suggest that reduced Prosaposin secretion after nerve injury may contribute to impaired regeneration rates. Hiraiwa et al. (2003) states that Prosaposin is an injury-repair protein acting on both neurons and glia and their data suggest the expression and processing of Prosaposin mRNA may be crucially regulated for cerebral homeostasis and nerve regenative and degenerative processes. The saposins (Sap) A-D are produced via proteolysis of the approximately $70 \mathrm{kDa}$ precursor protein and consist of 80 amino acids with a molecular weight of approximately $12-15 \mathrm{kDa}$. The saposins act as enzymatic activators in multiple stages of lysosomal sphingolipid degradation and membrane digestion (Tamargo et al., 2012). Taylor et al. (2000) reported the development of prosaptide peptides that are based on the 14-amino-acid neurotrophic sequence of human Prosaposin and, like the precursor protein, have been shown to have potent neurotrophic and neuroprotective properties that improved nerve regeneration. These studies indicate the potential of producing natural therapeutic compounds for the treatment of neurodegenerative diseases such as Alzheimer's and Parkinson's diseases. Other studies, have evaluated the potential of Prosaposin as an important molecule in the protection of cancer cells, such as prostate (Koochekpour et. al, 2012) and breast cancer cells (Wu et al, 2012), enabling them to survive and proliferate, also suggesting the presents of Prosaposin as a potential drug target in the development of treatments for personal cancer therapies.

Patton et al. (1997) demonstrated the presence of Prosaposins in human, cow and goat's milks. This study did not detect mature saposins. The bovine saposin C segment is required for neurotrophic activity. Neurotrophic effects of nanomolar quantities of this protein have been reported (Ham, 2004). While the human and bovine Prosaposin have been isolated and characterized, caprine Prosaposin and its related proteins have not been characterized.

In this study, a rapid and simple method was developed to assess the presence of Prosaposin and its mature saposins in the whey fraction of fresh milk from nine breeds of goats.

\section{MATERIALS AND METHODS}

\subsection{Collection of Milk}

Milk samples were collected in sterile tubes at the North Carolina A\&T State University farm from several breeds of goats (Alpine, Boer, Spanish, SpanishXBoer) and from local farms (Kiko, LaMancha, Nigerian Dwarf and Oberhasli) in collaboration with Dr. Niki Whitley of the North Carolina A\&T Cooperative extension. Bovine milk samples were collected from Holstein Fresian cows at the North Carolina A\&T State University farm and used as positive controls.

\subsection{Whey Fractionation}

Crude whey fractions were prepared by centrifugation @ $50000 \mathrm{XG}$ for 15 minutes in a Beckman ultracentrifuge using Beckman heat sealed tubes. The whey fractions were removed using sterile syringes connected to a 20 gauge needle. The extracts were stored at $-80^{\circ} \mathrm{C}$ until use.

\subsection{Sodium Dodecyl Sulfate-Polyacrylamide Gel Electrophoresis (SDS-PAGE)}

A volume of crude whey protein extract was added to an equal volume of $2 \mathrm{X}$ treatment buffer $(0.025 \mathrm{~m}$ Tris $\mathrm{pH}$ 8.0, $0.192 \mathrm{~m}$ Glycine, $0.1 \%$ SDS (Laemmli) and the samples were boiled for $2 \mathrm{~min}$ to denature the proteins. The protein samples were separated on $12.5 \%$ SDS phastgels (GE Healthcare) using the Phastsystem ${ }^{\circledR}$ and on a $12.5 \%$ slab gel (Hoeffer).

\subsection{Silver Staining}

The $12.5 \%$ slab gel was stained according to Tsai and Frasch (1982).

\subsection{Immunoblotting}

The proteins were transferred from the gels to pre-wet $0.22 \mu$ nitrocellulose by diffusion blotting. The nitrocellulose membrane and gel sandwich were placed in a moist chamber and incubated $20 \mathrm{~min} @ 70^{\circ} \mathrm{C}$. The membrane was blocked for $1 \mathrm{~h}$ in a solution of $3 \%$ bovine serum albumin and probed with polyclonal anti-prosaposin (Proteintech Group, Inc., IL) and anti saposin A, B, C and D 
(Santa Cruz Biotechnology, Inc., CA), respectively, for $1 \mathrm{~h}$. The membranes were washed for $5 \mathrm{~min}$ in $\mathrm{dH}_{2} \mathrm{O}$, followed by two 5 min washes in $1 \mathrm{X} \mathrm{KP}$ Wash (Kirkegaarde and Perry). The membranes were then incubated in HRP conjugated goat anti-rabbit second antibody (Bio-Rad Laboratories, Inc., CA 1:3000) and HRP conjugated donkey anti-goat (Santa Cruz 1:2000), respectively, for $1 \mathrm{~h}$. Proteins were detected using a tetramethylbenzidine substrate system (Kirkegaarde and Perry).

\section{RESULTS}

\subsection{Electrophoresis of Milk Proteins}

Milk contains multiple proteins that have potential therapeutic properties. Multiple protein bands ranging from 205 to $6.5 \mathrm{kDa}$ were detected in goat milk whey protein extract following silver staining (Fig. 1). More bands were observed at the same molecular weight as $\alpha \mathrm{S} 1$ casein proteins in bovine milk than in caprine milk as seen in lane 10 .

In the present study, the $12.5 \%$ SDS-PAGE on the Phastsystem, diffusion blotting and immunoblotting using antibodies to human Prosaposin and saposins was a simple and fast approach for detection. Prosaposin was detected by immunoblot analysis using polyclonal rabbit antiProsaposin (Proteintech) in milk of all breeds of goats selected for the study and in milk of cows (control). A 70$65 \mathrm{kDa}$ band was observed for Alpine, Spanish, SpanishXBoer and Spanish Nubian, Kiko, LaMancha, Nigerian Dwarf and Oberhasli breeds, Fig. 2a and b. A 12-14 kDa band similar in molecular weight to saposin $\mathrm{C}$ was also observed. Prosaposin was detected at varying levels in cow milk compared to goat milk (Fig. 3). The 12$14 \mathrm{kDa}$ saposin $\mathrm{C}$ band observed in milk of five cows was more difficult to detect than in goat milk. The PSAP antibody used is said to be cross-reactive with saposin C.

$\begin{array}{llllllllll}1 & 2 & 3 & 4 & 5 & 6 & 7 & 8 & 9 & 10\end{array}$

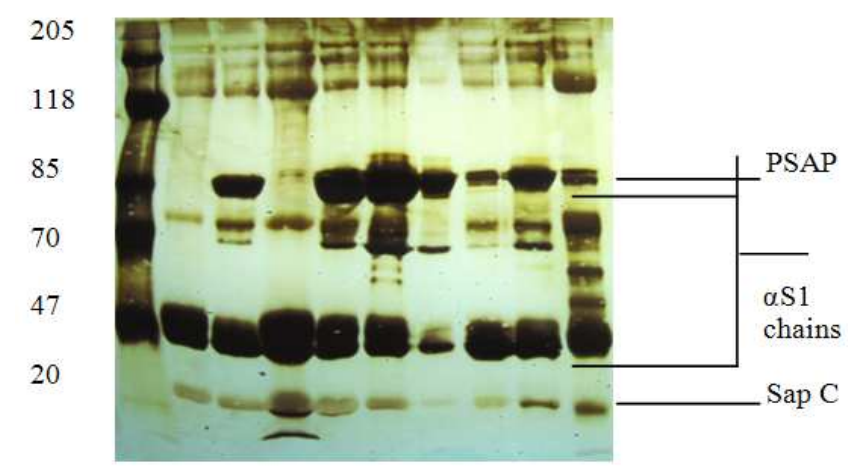

Fig. 1. Silver Stained Sodium Dodecyl Sulfate Polyacrylamide Gel of goat and cow crude whey fractions: Lane 1- Fisher protein markers, Lane 2-Alpine, Lane 3-Boer, Lane 4-Spanish, Lane 5-SpanishXBoer, Lane 6-Kiko, Lane 7-LaMancha, Lane 8Nigerian Dwarf, Lane 9-Oberhasli, Lane 10-Holstein Fresian cow

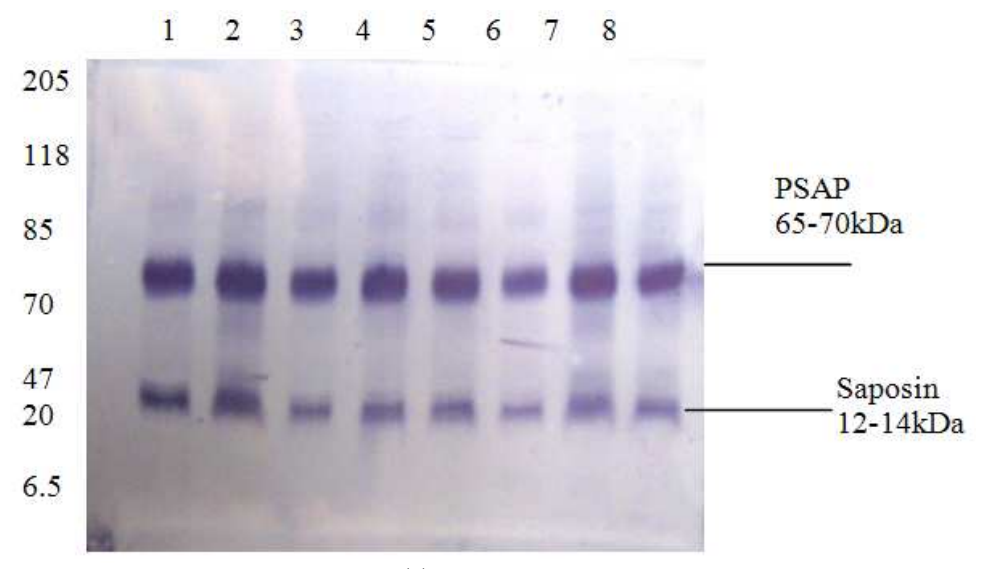

(a) 


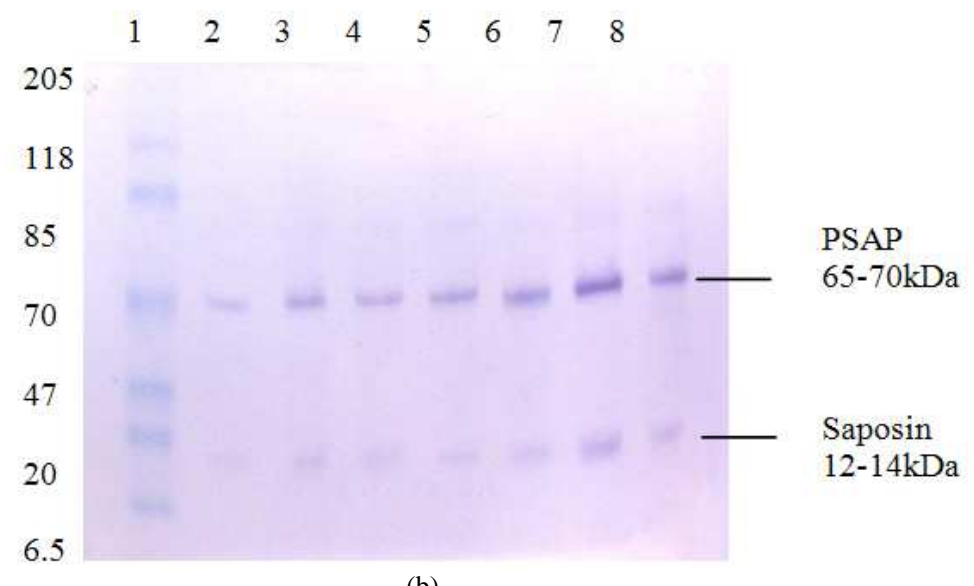

(b)

Fig. 2. (a) Immunoblot profiles of PSAP and saposin $C$ in goat crude whey fraction probed with anti-human PSAP: Lane 1Alpine, Lane 2-Boer, Lane 3-Boer, Lane 4-Spanish, Lane 5-SpanishXBoer, Lane 7-SpanishXBoer, Lane 8-SpanishXBoer (b) Immunoblot profiles of PSAP and saposin $\mathrm{C}$ in goat crude whey fractions probed with anti-human PSAP: Lane 1Fisher Protein markers, Lane 2-Alpine, Lane 3-Boer, Lane 4-Spanish, Lane 5- Kiko, Lane 6- LaMancha, Lane 7- Nigerian Dwarf, Lane 8-Oberhasli

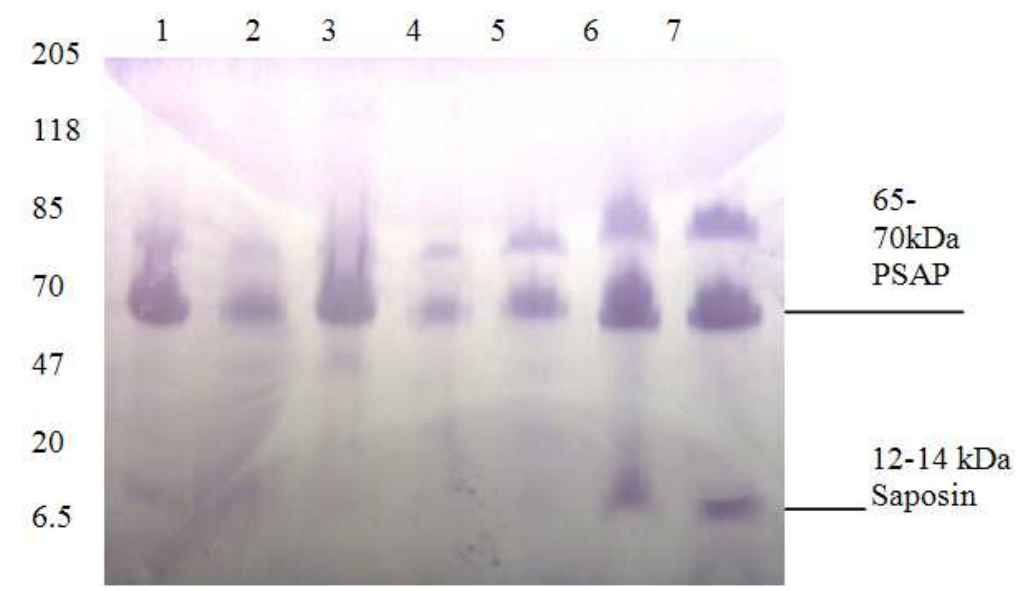

Fig. 3. Immunoblot profiles PSAP and saposin $\mathrm{C}$ in cow and goat whey fractions probed with anti-human PSAP : Lane 1- Holstein Fresian cow, Lane 2-Holstein Fresian cow, Lane 3- Holstein Fresian cow, Lane 4-Holstein Fresian cow, Lane 5-Holstein Fresian cow, Lane 6-Spanish goat, Lane 7-Boer goat

\subsection{Detection of Saposins}

The mature proteins, saposin A, B, C and D approximately $12-14 \mathrm{kDa}$, were detected in goat's milk (Fig. 4).

\section{DISCUSSION}

A rapid and simple method for the detection of Prosaposin and its mature saposins was accomplished using the Phastsystem (GE Healthcare Bio-Sciences AB, Piscataway, USA). These proteins were detected using cross reactive antibodies that may prove useful in studies on the possible health benefits and nutritional properties of goat milk for man The approach included separation of the fat, the whey and casein fraction from fresh goat and cow milk using high speed centrifugation at $50,000 \mathrm{xg}$ without adjusting the milk $\mathrm{pH}$ to 4.6 produced a crude whey 
fraction sufficient for the detection of Prosaposin. There was a clear distinction between the different layers. Patton reported that binding to concanavalin A, retention by anion-exchange cellulose and resistance to precipitation by heating was a useful system for isolation of Prosaposin in milk. Kunz and Lonnerdal (1989), concluded that separation of human milk into fat, whey and casein by centrifugation without prior $\mathrm{pH}$ adjustment does not yield distinct layers. The whey fraction was easily removed by inserting a needle attached to a syringe into the whey layer and slowly removing the whey portion. The whey fraction was resolved on a $12.5 \%$ SDS phastgel for approximately $20 \mathrm{~min}$. Diffusion blotting at $70^{\circ} \mathrm{C}$ for $20 \mathrm{~min}$ allowed for an efficient transfer of proteins from the SDS gel to the $0.2 \mu$ nitrocellulose membrane. Milk is an excellent source of nutrients and exhibits a range of biological activities that influence digestion, metabolic responses to absorbed nutrients, growth and development of specific organs and resistance to disease. Goat milk's chemical structure is remarkably similar to human milk, without the fat content found in cow milk. Milk proteins are conserved in different mammals. In this study the major proteins were present in goat milk (Park, 1994). Previous studies have indicated that like cow milk goat's can be a source of Prosaposin. However, these studies did not use fresh goat milk from diverse breeds of goats as tested in this study. According to a study by O'Brien et al. (1995), the active region of prosaposin is in the saposin $\mathrm{C}$ domain. The active sequence of saposin is a linear 12-mer peptide located in the $\mathrm{NH}_{2}$-terminal sequence of saposin $\mathrm{C}$ (LIDNNTEKEIL). The present study has identified cross reactive antibodies that can be used to detect goat milk saposin C by Western blot. Saposin A, B and D were also detected. Reports by Hinero et al. (1991) indicate that they were unable to detect mature saposins A, B, C and $\mathrm{D}$ in human milk.

The presence of the saposin C segment in goat's milk may indicate enhanced neurotrophic activity to benefit human nutrition (O'Brien et al., 1994) and thus further studies on concentration are needed. From the intensity of the bands for Prosaposin on Western blots, Prosaposin concentrations in goat and cow milk appear to be in the same range (Fig. 2a and b). These results are similar to those of the cow (Kunz and Lonnerdal, 1989). The intensity of the saposin $\mathrm{C}$ band in goats (Fig. 3) suggests the presence of saposin $C$ to be of a greater magnitude. The total protein concentration of saposin C may be higher in goat's milk than cow's milk. Saposin C was not detected in large quantities or was not presence in fresh cow's milk in this study. All saposins were detectable for the first time at approximately 12-15 kDa (Fig. 4).

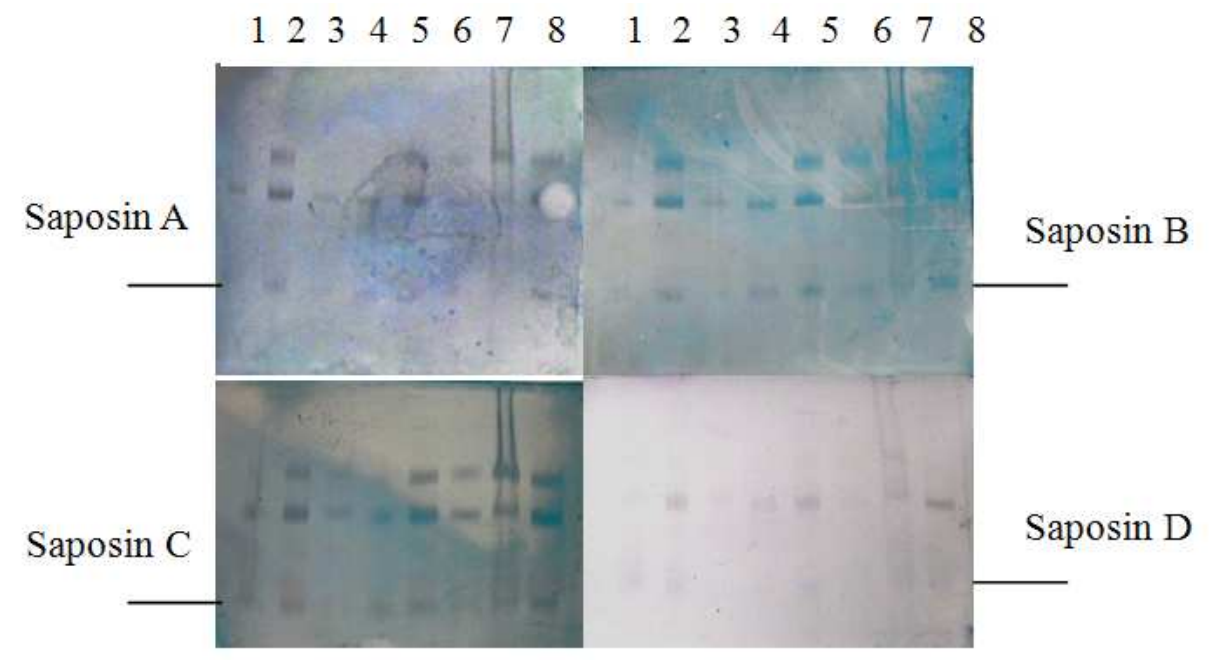

Fig. 4. Immunoblot profiles PSAP and saposin A, B, C and D in goat whey fractions probed with anti-human saposin A, anti-mouse saposin B, anti-human saposin C and anti-mouse saposin D, respectively and clockwise. Lane 1-Alpine, Lane 2-Boer, Lane 3-Spanish, Lane 4-SpanishXBoer, Lane 5-Kiko, Lane 6-LaMancha, Lane 7-Nigerian Dwarf, Lane 8-Oberhasli 
The antibodies used in this study were affinity purified for specific regions of PSAP and saposins (Santa Cruz Biotechnology, CA). The reactivity of these affinity purified goat anti-human, rabbit anti-human and goat anti-mouse antibodies to detect Prosaposin and saposins suggest antibody cross-reactivity for human, mouse, cow and goat Prosaposin and that the Prosaposin protein sequence is possibly conserved among species. The whey protein fraction of goat milk appears to be a convenient source of Prosaposin and saposin C. As a neurotrophic factor, milk Prosaposin may play a significant role in the development, maintenance and possibly restoration of the nervous system of mammals. Studies have shown that breed, stage of lactation, season of kidding and parity has a significant effect on milk composition (Chessa et al., 2009). Further studies including consideration of such factors will aid in the determination of the role of Prosaposin and mature saposins in goat and human nutrition, its potential benefits for human health and the treatment of neuropathic diseases.

\section{CONCLUSION}

A fast and simple method for the detection of goat Prosaposin and saposin A,B,C and D is reported. This method will aid in assessing goat milk proteins for the development of nutraceuticals or quality control and will aid in future studies of Prosaposin in goats and other animals. These proteins were detected using cross reactive antibodies that may prove useful in studies on the possible health benefits and nutritional properties of goat milk for man. The biological activity of saposins such as the neurotrophic activity of goat saposin $\mathrm{C}$ needs further characterization. The presence of the Prosaposin and the saposin proteins in goat milk may be associated with the reported health benefits of goat milk. Because of the potential of producing natural therapeutic compounds for the treatment of neuro-degenerative diseases extracted from the whey fraction, heat stability is necessary. Therefore, heat stability studies will be conducted. Other studies will be the identification and sequencing of the goat Prosaposin gene and the evaluation of genetic variation on the concentration of Prosaposin. These studies will contribute to our knowlegde of the therapeutic benefits of goat milk to aid producers in maintaining breeds with the potential to produce Prosaposin.

\section{ACKNOWLEDGMENT}

This study was supported in part by Dr. Mulumebet Worku and the Energy and Environmental Systems Doctoral Program at North Carolina Agricultural and Technical State University in Greensboro, North Carolina. I thank Dr. Niki Whitley of the Cooperative Extention Program in the School of Agriculture at North Carolina Agriculture and Technical State University for providing milk samples from local goat farms. I thank the personnel at the North Carolina Agricultural and Technical State University farm for their assistance with this project.

\section{ADDITIONAL INFORMATION}

\subsection{Funding Information}

This research was supported with funding from Title III and the School of Agricultural an Environmental Sciences (SAES) Agricultural Research Program and was IACUC approved.

\section{REFERENCES}

Chessa, S., F. Chiatti, G. Rignanese, G. Ceriotti and A. Caroli, 2009. Nutraceutical properties of goat milk: In silico analysis of the casein sequences. Options Mediterraneennes, 91: 241-243.

Haenlein, G., 2004. Goat milk in human nutrition. Small Ruminant Res., 51: 55-163. DOI: 10.1016/j.smallrumres.2003.08.010

Ham, D., 2004. Prosaposin precursor protein: Functions and medical applications. Scripta Med., 77: 127-134.

Hinero, T., A. Sano, K. Kondoh, S. Ueno and Y. Kakimoto et al., 1991. Secretion of sphingolipid hydrolase activator precursor, prosaposin. Biochem. Biophys. Res. Communi., 176: 668-674. DOI: 10.1016/S0006-291X(05)80236-0

Hiraiwa, M., J. Liu, A. Lu, C. Wang and R. Misasi, 2003. Regulation of gene expression in response to brain injury: enhanced expression and alternative splicing of rat prosaposin (sgp-1) mrna in injured brain. J. Neurotrauma, 20: 755-765. DOI: 10.1089/089771503767869980

Jolivalt, C.G., Y. Vu, L.M. Mizisin, A.P. Mizisin and N.A. Calcutt, 2008. Impaired prosaposin secretion during nerve regeneration in diabetic rats and protection of nerve regeneration by a prosaposinderived peptide. J. Neuropathol. Exp. Neurol., 67: 702-10. DOI: 10.1097/NEN.0b013e31817e23f4 
Koochekpour, S., S. Hu, C. Vellasco-Gonzalez, R. Bernardo and G. Azabdaftari et al., 2012. Serum prosaposin levels are increased in patients with advanced prostate cancer. Prostate, 72: 253-269. DOI: 10.1002/pros.21427, PMID: 21630292

Kunz, C. and B. Lonnerdal, 1989. Human milk proteins: separation of whey proteins and their analysis by polyacrylamide gel electrophoresis, Fast Protein Liquid Chromatography (FPLC) gel filtration and anion-exchange chromatography. Am. J. Clin. Nutrit., 49: 464-470. PMID: 2923079

O'Brien, J., G. Carson, H. Seo, M. Hiraiwa and Y. Kishimoto, 1994. Identification of prosaposin as a neurotrophic factor. Proc. Natl. Acad. Sci., 91: 9593-9596. DOI: 10.1073/pnas.91.20.9593

O'Brien, J., G. Carson, H. Seo, M. Hiraiwa and S. Weiler et al., 1995. Identification of the neurotrophic factor sequence of prosaposin. FASEB J., 9: 681-685. PMID: 7768361

Park, Y., 1994. Hypo-allergenic and therapeutic significance of goat milk. Small Ruminant Res.,14: 151-159. DOI: 10.1016/0921-4488(94)90105-8

Patton, S., G. Carson, M. Hiraiwa, J. O'Brien and A. Sano, 1997. Prosaposin, a neurotrophic factor: Presence and properties in milk. J. Dairy Sci., 80: 264-272. DOI: 10.3168/jds.S0022-0302(97)75934-4
Slacanac, V., R. Bozanic, J. Hardi, J. Szabo and M. Lucan, 2010. Nutritional and therapeutic value of fermented caprine milk. Soc. Diary Technol., 63: 171-189. DOI: 10.1111/j.1471-0307.2010.00575.x

Tamargo, R., A. Velayati, E. Goldin and E. Sidransky, 2012. The role of saposin $\mathrm{C}$ in Gaucher disease. Mol. Genet. Metab.,106: 257-263. DOI: 10.1016/j. ymgme.2012.04.024

Taylor, E., D. Otero, W. Banks and J. O'Brien, 2000. Retro-inverso prosaptide peptides retain bioactivity, are stable in vivo and are blood- brain barrier permeable. J. Pharmacol., 295: 190-194.

Tsai, C.M. and C.E. Frasch, 1982. A sensitive silver stain for detecting liposaccharides in polyacrylamide gels. Analytical Biochemi., 119: 115-119. DOI: 10.1016/0003-2697(82)90673-X

Wu, Y., L. Sun, Z. Weiying, J. Xu and H. Liu et al., 2012. Prosaposin, a regulator of estrogen receptor alpha, promotes breast cancer growth. Cancer Science, 110: 1820-1825. DOI: 1111/j.13497006.2012.02374.x 